\title{
Analysis and Enlightenment of College Students' Demand for Entrepreneur Tutors*
}

\author{
Ying Jin \\ School of Politics and Public Administration \\ Southwest University of Political Science and Law \\ Chongqing, China 401120
}

\begin{abstract}
With the advancement of college students' innovation and entrepreneurship policy, while the entrepreneurial enthusiasm of college students is constantly improving, the shortcomings of entrepreneurial quality are gradually exposed, and the need for entrepreneurial guidance is increasingly strong. Based on the current situation of college students' entrepreneurial quality and training, this paper investigates and analyzes the needs of college students for the recognition of entrepreneurial tutors, guidance content, quality structure, personnel composition, etc., providing many inspirations for building entrepreneurial tutors team and forming a systematic entrepreneurial training system.
\end{abstract} team

Keywords—college students' entrepreneurship; demand; tutor

\section{INTRODUCTION}

Innovative entrepreneurial talent training has become an important measure for China's talent development strategy. In recent years, Chinese universities have also actively responded to this strategy. They have made efforts in fund matching, entrepreneurship platform, curriculum setting, etc., in order to create a more favorable environment for innovation and entrepreneurship, thus setting off a new wave of college students' innovation and entrepreneurship. While participation is in the increasing enthusiasm, it is necessary to pay attention to the obstacles and failures of most college students in the process of starting a business. Among the factors that affect the success or failure of college students' innovation and entrepreneurship, funds, institutions, and opportunities are important, but entrepreneurial knowledge and ability are more critical, and the accumulation of such strengths requires not only a unified curriculum education, but also in-depth and detailed guidance. Especially for college students who have no entrepreneurial experience. Therefore, entrepreneurial instructors have played an extremely important role in answering questions, sharing experiences, and offering inspiration and help. Only by forming a strong team of entrepreneurial mentors can the training links of innovation and entrepreneurship, such as classroom teaching, project guidance and practice be integrated and be systematically guided. However, under the traditional educational philosophy and framework of conveying knowledge, the development of college entrepreneurial tutor team is not smooth, facing many

*Fund projects: 2015 reform research project of higher education of Southwest University of Political Science and Law (No.2015C30). problems such as unclear roles, unclear responsibilities, single source, insufficient experience, loose management, and lack of enthusiasm, which has seriously affected the sustainable development of college students' entrepreneurial practice, and has caused most college students' spontaneous entrepreneurial projects to stagnate in the initial stage. Clarifying the needs for the instructors in the process of entrepreneurship to create a high-quality entrepreneurial mentor team in a targeted manner has long-term significance for the cultivation of innovative and entrepreneurial talents in China and the national innovative development strategy.

\section{The QuAlity of COLlege Students' ENTREPRENEURSHIP AND THE CURRENT SITUATION OF TRAINING}

The entrepreneurial quality of college students determines the success or failure of entrepreneurship, and also determines their level of demand for entrepreneurial guidance. As a frontline position for training college students, do colleges and universities cultivate their entrepreneurial awareness and ability to meet the entrepreneurial needs of college students? Grasping the basic situation is conducive to a better understanding of the entrepreneurial guiding needs of college students.

\section{A. Insufficient Entrepreneurial Quality of College Students}

In the case of successful entrepreneurship of college students, most entrepreneurs have a solid family background and economic strength. They can get help from parents and family-related companies in their entrepreneurship process. And only a few people can be lucky to get help from government and social enterprises. Those who enter the market only with their own abilities and gain a foothold are particularly rare. Entrepreneurship should be based on the expertise of industry, products and management operations, and more importantly, it must be based on entrepreneurial capabilities. The entrepreneurial abilities include predictive judgment ability, problem solving ability, risk resistance ability, team cooperation ability, leadership management ability, language communication ability, etc., and they have very strong comprehensive characteristics. Therefore, the improvement of entrepreneurial quality requires not only relevant knowledge reserves, but also the accumulation of experience brought about by continuous practice and reflection 
Because the systematic curriculum of Chinese college students' entrepreneurship is still blank, entrepreneurial college students mostly rely on imagination to explore and lack comprehensive quality matching with entrepreneurship. In recent years, some colleges have experienced "sports-style" entrepreneurship ["sports-style" entrepreneurship refers to the lack of independent thinking and just follow-up entrepreneurial ${ }^{1}$ tendency [1]. whether it is to avoid employment pressure, blindly investing in entrepreneurship in the absence of rational considerations of its own quality, ability and environment, just illustrates the lack of entrepreneurial ability. This also proves that more professional entrepreneurial guidance and training is the need of college students to start a business [2].

\section{B. Lack of Entrepreneurship Training in Colleges}

Foreign entrepreneurship education started early and has been highly valued by the government, universities and society. It has been quite large, and has a systematic curriculum system, perfect entrepreneurship education materials and entrepreneurial education lecturers with rich practical experience and entrepreneurial experience. . In comparison, China's entrepreneurship education started late, and the relevant policies are not perfect and enforceable. First, many colleges and universities do not have specialized entrepreneurship education courses, and entrepreneurship education has not yet been included in the talent cultivation system. Second, there is insufficient attention to the experience of students' entrepreneurial practice. Although there are entrepreneurial competitions and practical activities, the overall participation of students is low, the quality is often not high, and the radiation range is small. It is difficult to form an atmosphere of innovation and entrepreneurship among students. Third, there is a shortage of teachers who are engaged in entrepreneurship education and guidance. Many counselors and staff in the employment department have become part-time instructors in the entrepreneurship mentoring class. Due to insufficient professional knowledge reserves and the lack of tracking of cutting-edge information, the guidance effects tend to be poor. Even there are teachers who teach entrepreneurship courses, they are mostly engaged in theoretical teaching work for many years and their own entrepreneurial experience is very limited. Teaching based on basic knowledge is lacking in predicting the development of the entrepreneurial market and the form of teaching is single and rigid, so that it's difficult to attract students well, not to mention providing support for some of the entrepreneurial resources and channels. Fourth, there is no systematic team and management system. Through interviews with relevant personnel of some universities in Chongqing, it is found that most colleges do not have a system of entrepreneurial tutors. The guidance for college students' entrepreneurship is based on the students' innovative and entrepreneurial projects. The teachers sought by the students themselves are entrepreneurial instructors, which have obvious provisionality and transiency without fixed team. In response, there is no way to talk about the management of these instructors. There is no assessment, supervision, and evaluation. Some of the rewards are in a

"Sports-style" entrepreneurship refers to the lack of independent thinking and just follow-up entrepreneurial phenomena. purely obligatory state, while others have scattered incentives, lack of systematic design, so it is difficult to mobilize the participation enthusiasm of the tutor.

Therefore, in the absence of college students' own entrepreneurial quality, and the lack of systematic entrepreneurship, the desire of entrepreneurs with entrepreneurial aspirations for entrepreneurship guidance is greatly enhanced.

\section{COLLEGE STUDENTS' NEEDS FOR ENTREPRENEURIAL TUTORS}

The research designed the "College Students' Entrepreneurship Survey Questionnaire" to collect information on entrepreneurial awareness, entrepreneurial problems, and entrepreneurial guidance needs. The questionnaire was randomly sampled by college students, and 500 questionnaires were distributed with the final collection of 402 valid questionnaires. The effective collection rate of the questionnaire was about $80 \%$.

\section{A. The Demand Degree for Entrepreneurial Guidance}

Through a sample survey of college students, it is found that $80 \%$ of students have a positive opinion on whether "professional entrepreneurial tutor (team) is helpful to entrepreneurship" and only 1\% think it is not helpful, indicating that most of students have a high recognition for the value of entrepreneurship guidance, which is consistent with the findings of related research by Chen Fuqiang [3], Liu Feng [4] and other scholars. Further field investigations reveal that there are many student entrepreneurship projects in the shops or mobile stalls around the school, but there are few professional and high-quality projects, most of which are retail, service, tutoring, housekeeping and other low-tech businesses. There is very little use of professional knowledge or professional skills, especially for liberal arts students; even if based on professional skills and knowledge, the entrepreneurial students will try to avoid high-tech programs such as development and R\&D, or they will seek professionals to undertake. This is more common in college students' entrepreneurship in China. The knowledge of college students is mainly limited to the knowledge of their own majors and there are many kinds of knowledge reserves for entrepreneurial needs, which not only greatly reduces the scientific and technological conversion rate of college students' entrepreneurship, raises the risk, but also makes most of college students who have entrepreneurial ideas afraid to act because of lack of experience and guidance. Among the surveyed college students' entrepreneurial concerns, the lack of professional guidance accounts for $22 \%$, ranking second among many concerns (other rates of major concerns and choices are respectively: economic loss accounts for $24 \%$; lack of projects accounts for $19 \%$, less funds accounts for $12 \%$, the negative influence on study accounts for $10 \%$, the opposition of family members accounts for $5 \%$, etc.). It can be seen that college students have relatively great needs for entrepreneurship guidance from both consciousness and practice. 


\section{B. The Need for the Content of Entrepreneurial Guidance}

The vast majority of college entrepreneurs fails or gives up on the way forward. The main reason lies in the weakness of entrepreneurial literacy, and entrepreneurial literacy involves many aspects. The survey found that more than $80 \%$ of students want guidance on entrepreneurship ability, $73 \%$ of them want teachers to help select projects, $69.5 \%$ want guidance on entrepreneurial resources acquisition and integration, and $62 \%$ want to get more shared entrepreneurial experience to make up for their shortcomings. In addition, entrepreneurial awareness, entrepreneurial knowledge, entrepreneurial fund acquisition, entrepreneurial policies and regulations are all things that college students hope to be guided. Further interviews found that college students' expectation of entrepreneurial tutors is not only the convey of knowledge and experience, but also hopes to use the tutor's resource platform to obtain real help for their own entrepreneurs, for example, tutors recommend partners or investors in their entrepreneurial project selection process, and even form entrepreneurial teams, start a business salon, and other channels to promote entrepreneurship advance. From the perspective of time of guidance, these contents run through the whole process of entrepreneurship, especially in the initial stage. Therefore, entrepreneurial guidance not just means several simple lectures or courses before the start of business, but is based on the key needs of different entrepreneurial stages to carry out in the multi-content crossover and multistage tracking way.

\section{Demand for the Quality of Entrepreneurial Tutors}

In general, the requirements of college students for entrepreneurial tutors tend to be a combination of specialization and practicality. In the survey, the demand for tutors that "have successful entrepreneurial draft" and "have the entrepreneurial experiences" rank the first and third positions respectively, and the selection rates are as high as $94.5 \%$ and $79 \%$, which means that direct entrepreneurial experience is an important quality for becoming entrepreneurial tutor. In the second place, the instructor must have entrepreneurial knowledge, with a selection rate of $81 \%$. Due to the division of majors, college students often only learn some of the knowledge related to entrepreneurship, and the knowledge tends to be relatively shallow, so that they have no systemic and deep understanding of projects expertise, market planning, financial fund management, quality control, team operation, advertising, laws and regulations, etc. General knowledge is not systematically understood. There is no knowledge reserve for them, let alone the use of skills and abilities. Therefore, the knowledge demand for entrepreneurial tutors just reflects the shortcomings of basic knowledge of college students. However, there is low operability to hope that every entrepreneurial tutor will have multiple kinds of knowledge, which demands for building a team of entrepreneurial instructors and integrating the knowledge structure of team members. For the entrepreneurial resources of entrepreneurial tutors, $71 \%$ of the respondents put forward the demand, which is consistent with the above-mentioned needs for guiding content. Only the tutors have certain entrepreneurial resources, they can provide better guidance and even provide them directly. In addition, college students have higher requirements for the communication skills of entrepreneurial tutors (the selection rate is $56 \%$ ), because the tutor is not a direct executor of entrepreneurship, and its guidance is mainly achieved through communication through various channels and methods. Even for a highly experienced and knowledgeable mentor, if he can't accurately convey ideas and provide guidance in a way that college students are good at understanding and accepting, it is meaningless. On the whole, entrepreneurial instructors need to have the experience, knowledge and awareness of entrepreneurs, but also to maintain the characteristics of the "teachers" to give the systematic guidance.

\section{Demand for the Personal Composition of Entrepreneurial Mentors}

The source of the entrepreneurial tutor is related to the tutor's knowledge structure, experience value, coaching ability, and resource network. According to the diversified needs of college students for entrepreneurial guidance content and the quality of tutors, it is difficult to find mentors with all qualities from a single source, so the introduction of tutor power through multiple channels becomes necessary. In the survey, on the choice for the source of entrepreneurial tutors, college students mainly prefer school teachers (selection rate of 67\%), successful entrepreneurs (selection rate of 59\%) and national certified entrepreneurial trainers (selection rate of $45 \%$ ), and government officials and experienced seniors take up very few proportion. School teachers are regarded as the first choice, which reflects that college students are entrepreneurial groups; successful entrepreneurs and nationally certified entrepreneurial trainers may be either school teachers or offcampus personnel, indicating that college students are willing to accept off-campus resources, which lays the foundation for introducing teachers with multiple channels and building up the mentor team.

\section{ENLIGHTENMENT ON COLLEGE STUDENTS' ENTREPRENEURSHIP}

The demand for entrepreneurial guidance in college students' entrepreneurial process is diversified. It is difficult to meet the needs through one or two courses and one or two allround instructors. Therefore, it is necessary to build a team of entrepreneurial tutors who can take root in students, facilitate communication, and comprehensively offer guidance. Cooperating with systematic entrepreneurship courses and practical practice venues, a systematic and complete system of college students' entrepreneurial quality training should be formed.

\section{A. The Entrepreneurship Mentor Team}

1) Staged guidance for the whole process: The establishment of the team of entrepreneurial instructors is to provide professional guidance for the whole process of college students' entrepreneurship. In view of the characteristics of college students' entrepreneurship, they strengthen the students' entrepreneurial awareness, find entrepreneurial projects, and accumulate basic knowledge and ability of entrepreneurship during the preparation period of 
entrepreneurship; guide the establishment of entrepreneurial institutions, system establishment, project operation, personnel selection, etc. in the initial stage of entrepreneurship; guide institutional optimization, business development, strategic adjustment, etc. in the steady period of entrepreneurship; carry out the development planning and psychological adjustment counseling for college students with terminated or failed entrepreneurship in summary period.

2) Pluralistic role: Because of the whole process of guidance, the role of the mentor team is more diverse. They are motivators who motivate students to innovate and start a business; they are imparters who impart knowledge, experience, and skills related to entrepreneurship; they are consultants who help solve problems in the entrepreneurial process, including psychological adjustment and role transition. These role-playing, as well as the depth of fulfillment of duties, ultimately depend on the attitude of the instructor. The team of entrepreneurial instructors should be a group of people who have a certain interest and enthusiasm for entrepreneurship, are willing to invest their energies in guiding college students to start a business, and gain a sense of acquisition and accomplishment because of the growth and development of students. Therefore, it is necessary not only to examine whether they can perform their duties when selecting personnel, but also to examine the subjective initiative of their performance.

3) Compound personnel composition: In view of the diversification of college students' entrepreneurial projects and the comprehensive qualities required for entrepreneurship, the sources of entrepreneurial tutors in colleges and universities should also be diverse, reflecting multidisciplinary integration, cross-school integration, and a combination of theoretical and practical type. Multidisciplinary integration is helpful for extensive participation of economic, management, political, legal, monetarily financial, corporate-based financial, network technology, marketing and other professional majors. Acrossschools unification assists to integrate the advantages of each university, and use the information of many regions to broaden the horizon of entrepreneurship and expand the resource platform. The combination of theoretical and practical type not only needs the college teachers with entrepreneurial experience, but also requires the business people who are starting a business, the professional managers who understand the operation of the enterprise, etc., to form complementation of knowledge and experience.

\section{B. The Guidance Model of Project System}

The members of the entrepreneurial mentor team are divided into different entrepreneurial steering groups based on entrepreneurial projects. The group consists of several teachers. The guiding work is based on the brewing of entrepreneurial projects, and there are two main types of entrepreneurial projects. First, students with entrepreneurial ideas apply for a team of entrepreneurial thinking, and second, the mentor team publishes entrepreneurial projects to recruit entrepreneurs after discovering entrepreneurial opportunities. Once the basic conditions of the project and personnel are ready, the guidance of entrepreneurial instructor team begins. The end point of the guidance work is also based on the project. The time for the guidance can be set first, with the fixed time or the results achieved by the project as the standard. However, if the entrepreneurial project fails, the psychological adjustment and experience summary of the entrepreneurial summary period shall be guided and the project ends. In the process of guiding, according to the process of the entrepreneurial project and its needs, it's crucial to adjust the instructors to match the appropriate guidance content, which not only ensures the unity of the whole process of the entrepreneurial project, but also meets the needs of diversified guidance.

\section{Multi-level Incentive System}

Through the dynamic evaluation system, the incentives for entrepreneurial college students are linked to the incentives of entrepreneurial tutors. At present, the entrepreneurial projects of college students are often half-baked. In the early stage, their applications tend to be very positive. And in the later stage, the relevant text materials are fully enriched, and the application can be completed. Yet, the actual implementation of the project plan is just a minority, so, the meaning of the entrepreneurial exercise is lost. Entrepreneurship instructors have neither clear guidance responsibility nor effective material and spiritual incentives, motivation and enthusiasm [5]. Therefore, it's better to establish a dynamic assessment and evaluation mechanism for college students' entrepreneurial projects and an assessment mechanism for the mentor team. And an interactive mechanism should be formed to track the implementation process of college students' entrepreneurial projects and make regular inspection, that is, the assessment of the responsibilities of the mentor's guidance; the success or failure should not be the evaluation standard of the entrepreneurial project, and the completion rate of implementation plan that has been committed shall be the core, emphasizing the implementation of the plan and the summary of gains and losses in practice. All of these will be used as a basis for evaluating the performance of the instructor, and are linked to fees and employment. For the teachers in the school, the tutor's guidance work can be linked to the teaching workload, which is divided into the amount of hours of the entrepreneurship education curriculum and the amount of instructional time for the guidance work under the project system; for the teachers outside the school, the compensation is paid according to the corresponding money amount of the workload within the school.

\section{Systematization of Entrepreneurship Courses}

Series of entrepreneurship courses should be added in colleges and universities instead of one or two scattered courses. It's necessary to carry out systematic teaching of entrepreneurial awareness education and entrepreneurial basic knowledge for college students to link knowledge and entrepreneurship of different professions through entrepreneurial cases, simulations, discussions, etc. so as to guide students to discover the value of theoretical knowledge in entrepreneurship, explore entrepreneurial projects, broaden entrepreneurial thinking and stimulate students' entrepreneurial 
willingness on a larger scale. What's more, it is helpful for the students in the embryonic stage of entrepreneurship to find ways and means to further advance. At the same time, through the establishment of entrepreneurship courses, the basic guiding responsibilities of the tutor team can be related to the teaching system, and the teaching management system shall be used to design the content, methods, assessment and expenses of the entrepreneurial teaching, which ensures the fulfillment of the tutor's guiding duties and corresponding continuous support of funds.

\section{E. The Improvement of Site Facilities Configuration}

The implementation and guidance of college students' entrepreneurial projects need to be supported by corresponding supporting facilities. On the one hand, hardware conditions include office space of entrepreneurial team, project display base, exchange discussion and guidance place, and professional venues involved in entrepreneurial projects, such as some entrepreneurial street and entrepreneurial incubator building set up by the university, which provide necessary support for the office and product display of the entrepreneurial team, and at the same time an entrepreneurial innovation atmosphere is created successfully. On the other hand, the operation of the site facilities also requires a soft system. In order to use the site efficiently, in addition to simple and convenient application and use specifications, the guidance and assistance activities should be placed in the venue, for example, setting up a team office of entrepreneurial instructors to collect the consulting needs of the entrepreneurial team at any time, conduct regular entrepreneurial exchanges, seminars and other activities, so that the entrepreneurial establishments can be "living", becoming a gathering place for entrepreneurial vitality and innovative ideas, so as to continue to publicize the innovation and entrepreneurship for college students. In the mean time, it has an attractive effect on off-campus resources.

\section{CONCLUSION}

The system of college students' entrepreneurial quality training is a systematic project. On the one hand, each component needs to be refined, especially the construction of the college students' entrepreneurial mentor team; on the other hand, the coordination between the various parts is also worth paying attention to. At the same time, with the increase of entrepreneurial practice and the improvement of overall quality, the change of entrepreneurial mentor team needs to be followed up.

\section{REFERENCES}

[1] Yan Yan. The Lack of Independent Thinking in Sports-Style Entrepreneurship Is the Biggest Waste of Social Resources.[2016-0527]http://www.chinaventure.com.cn/cmsmodel/news/detail/295425.sht M1 阎炎. 运动式创业缺乏独立思考, 这是对社会资源最大的浪费. [2016-05-27]

http://www.chinaventure.com.cn/cmsmodel/news/detail/295425.shtMl

[2] Li Tao. On College Students' Suspension for Business[J].Pioneering with Science \& Technology Monthly, 2008（7）:34-35 李涛.浅议大 学生休学创业[J].科技创业月刊, 2008 (7):34-35
[3] Chen Fuqiang. On the Role of Introducing Entrepreneurial Mentors in Reducing Entrepreneurship Risks of College Students.The Border Economy and Culture. 2014（4）陈馥强.论引入创业导师对降低大学 生创业风险的作用.边疆经济与文化. 2014（4)

[4] Liu Feng,Song Xiaoting,Wei Yifei. The Formation Mechanism of Guiding Behavioral Identity of Entrepreneurial Instructors.Science Studies.2015（8）刘凤,宋小婷,魏毅斐.创业导师指导行为认同形成 机理.科学学研究.2015 (8)

[5] Shu Lianlian. Research on Encouragement Mechanism of Entrepreneurial Tutor under the Perspective of Expectation Theory.Economic Research Guide.2014（10）舒恋恋.期望理论视角 下的创业导师激励机制研究.经济研究导刊.2014（10） 